\title{
PERSEPSI MAHASISWA TERHADAP PELAKSANAAN PEMBELAJARAN OPERASIONAL TATA BOGA
}

\author{
Eryd Saputra ${ }^{1}$, Ambiyar ${ }^{2}$, Wakhinuddin ${ }^{3}$ \\ ${ }^{1}$ Program Studi Manajemen Kuliner, Politeknik Pariwisata Batam, \\ Jalan Gajah Mada The Vitka City Complex, Kota Batam - 29426 \\ ${ }^{2,3}$ Fakultas Teknik, Universitas Negeri Padang, \\ Jalan Prof. Dr. Hamka, Air Tawar Barat, Kota Padang - 251711 \\ 1e-mail: saputra.eryd@gmail.com
}

\begin{abstract}
Abstrak
Tujuan penelitian adalah mengetahui persepsi mahasiswa terhadap mata kuliah pembelajaran Operasional Tata Boga terkait materi perkuliahan dan kompetensi dosen (pedagogik, profesional, kepribadian, dan sosial). Jenis penelitian adalah deskriptif dengan sampel sebanyak 30 mahasiswa angkatan 2019/2020. Penetapan sampel menggunakan purposive sampling. Instrumen penelitian menggunakan angket tertutup. Teknik analisis data mengunakan deskriptif kuantitatif. Berdasarkan hasil penelitian disimpulkan bahwa: (1) Berdasarkan persepsi mahasiswa, konstruksi materi telah sesuai dengan kebutuhan dan bermanfaat untuk meningkatkan keterampilan mahasiswa, meskipun ada beberapa materi yang cukup sulit untuk dipahami; dan (2) Kompetensi dosen pengampu mata kuliah Operasional Tata Boga sangat baik dan dapat dikategorikan sebagai seorang dosen profesional, namun tetap harus ada perbaikan atau peningkatan pada beberapa aspek.
\end{abstract}

Kata Kunci: persepsi mahasiswa, materi perkuliahan, kompetensi dosen.

\begin{abstract}
The purpose of this research was to determine students' perceptions of the courses in Operasional Tata Boga related lecture material and lecturer competencies (pedagogic, professional, personality, and social). This type of research was descriptive with a sample of 30 students class of 2019/2020. Determination of the sample used purposive sampling. The research instrument used a closed questionnaire. Data analysis techniques used quantitative descriptive. Based on the results of the research it was concluded that: (1) Based on students' perceptions, the construction of the material was in accordance with the needs and was useful for improving student skills, although there were some materials that were quite difficult to understand; and (2) The competence of lecturers in the Operasional Tata Boga course is very good and can be categorized as a professional lecturer, but there must still be improvements in several aspects.
\end{abstract}

Keywords: student perception, lecture material, lecturer competences.

\section{PENDAHULUAN}

Kemajuan sebuah bangsa banyak dipengaruhi oleh sektor pendidikan. Pendidikan yang merata bagi seluruh masyarakat menjadi pondasi yang kuat untuk kemajuan bangsa. Pemerintah secara terus menerus berusaha membangunan sektor pendidikan, khususnya kualitas pendidikan agar dapat menghasilkan sumber daya manusia yang berkualitas, produktif, dan kreatif. Hal yang sangat 
penting dalam pendidikan adalah pembelajaran. Proses pembelajaran adalah interaksi antara dosen, mahasiswa, dan bahan ajar. Peran dosen sangat penting dalam mencapai keberhasilan pembelajaran. Oleh karenanya, dosen harus memiliki empat kompetensi, yaitu pedagogik, kepribadian, sosial, dan profesional (Undang-Undang Nomor 14 Tahun 2005). Keempat kompetensi tersebut harus seimbang, agar tercipta proses belajar-mengajar yang berkualitas. Selain kompetensi, ada juga komponen lain yang perlu diperhatikan seperti bahan ajar, cara mengajar, cara melakukan evaluasi, serta proses pembelajaran. Evaluasi wajib dilaksanakan oleh dosen agar dapat mengetahui tingkat keberhasilan proses belajar-mengajar, serta keselarasan bahan ajar dan hasil belajar mahasiswa. Seperti halnya dalam mata kuliah Operasional Tata Boga yang harus diampu oleh dosen yang memiliki kompetensi yang lengkap dan paham akan semua proses pembelajaran dengan baik.

Operasional Tata Boga merupakan salah satu mata kuliah inti pada Program Studi Manajemen Kuliner Politeknik Pariwisata Batam. Berdasarkan pada mata kuliah tersebut, mahasiwa diharuskan memahami tentang teknik dasar memasak dan berkemampuan untuk mengaplikasikan seluruh konsep dasarnya. Mata Kuliah Operasional Tata Boga memiliki beberapa dosen pengampu dengan pendidikan dan pengalaman mengajar yang berbeda, hal tersebut akan memengaruhi hasil akhir dari pembelajaran mata kuliah tersebut.

Peneliti ingin berkontribusi bagi pengembangan pembelajaran di Program Studi Manajemen Kuliner melalui analisis persepsi mahasiswa terhadap pelaksanaan pembelajaran Operasional Tata Boga. Beberapa hal dalam pembelajaran yang dapat memengaruhi persepsi mahasiswa diantaranya materi perkuliahan dan kompetensi dosen (yang mencakup kompetensi pedagogik, profesional, kepribadian, dan sosial). Persepsi merupakan sebuah kemampuan memaknai sesuatu yang dimulai dengan membedakan, mengelompokkan serta memfokuskan pada suatu objek tertentu (Sarwono, 2013). Persepsi tersebut dapat terjadi pada saat penerimaan rangsangan eksternal yang dirasakan oleh otak. Semua rangsangan yang dirasakan oleh panca indra, namun tidak semua mempunyai daya tarik yang sama, hal tersebut yang dapat membuat terjadinya 
persepsi yang berbeda dari setiap orang. Perbedaaan persepsi dipengaruhi oleh faktor dari dalam dan luar diri. Faktor dalam berupa keinginan, penilaian, pengalaman, dan harapan. Sedangkan faktor luar sifat rangsangan dan situasi area sekitar (Prasetijo dan Ihwalauw, 2005). Terdapat tiga komponen dalam persepsi, yaitu kognitif, afektif, dan konotatif (Walgito, 2010). Ketiga komponen tersebut akan memengaruhi persepsi seseorang. Perbedaan persepsi dapat memengaruhi pandangan seseorang terhadap suatu objek, serta akan berdampak pada tindakan seseorang.

Hasil penelitian yang pernah dilakukan memperlihatkan bahwa keempat kompetensi dosen dikategorikan pada level baik meski ada satu kompetensi yang dianggap mahasiswa masih kurang (Soraya, 2018). Sedangkan penelitian yang peneliti lakukan di Program Studi Manajemen Kuliner Politeknik Pariwisata Batam bertujuan untuk mendeskripsikan persepsi mahasiswa terhadap pelaksanaan pembelajaran Operasional Tata Boga, yang terdiri materi perkuliahan dan kompetensi dosen (pedagogik, profesional, kepribadian, dan sosial).

\section{METODE}

Metode penelitian yang digunakan adalah deskriptif kuantitatif. Data yang diperoleh dari penelitian dianalisis serta diinterpretasikan agar mudah dipahami. Lokasi penelitian di Program Studi Manajemen Kuliner Politeknik Pariwisata Batam. Responsden penelitian adalah mahasiswa Program Studi Manajemen Kuliner Politeknik Pariwisata tahun akademik 2019/2020 dengan jumlah 30 orang. Jumlah responsden $10 \%$ dari populasi mahasiswa Program Studi Manajemen Kuliner Politeknik Pariwisata tahun akademik 2019/2020. Penetapan sampel menggunakan metode purposive sampling. Instrumen yang dibuat berupa angket tertutup dengan menggunakan Skala Likert.

Tabel 1 Skala Likert

\begin{tabular}{cc}
\hline Kriteria & Skala \\
\hline Sangat Tidak Baik/Sangat Rendah/Tidak Pernah & 1 \\
Tidak Baik/Rendah/Jarang & 2 \\
Biasa/Cukup/Kadang-Kadang & 3 \\
Baik/Tinggi/Sering & 4 \\
Sangat Baik/Sangat Tinggi/Selalu & 5 \\
\hline
\end{tabular}


Penyusunan item pertanyaan/pernyataan disesuaikan dengan indikator permasalahan dan divalidasi. Uji validitas dilakukan dengan cara menghitung korelasi Pearson, dengan kriteria valid apabila $r_{\text {hitung }}>r_{\text {tabel }}$ atau dengan nilai signifikansi $<0,05$. Uji Reliabilitas akan diukur dengan cara memakai rumus Cronbach Alpha, dengan kriteria apabila nilainya kurang dari 0,60, maka dinyatakan gugur atau tidak reliabel. Data penelitian diolah secara deskriptifkuantitatif dengan menarasikan informasi yang disampaikan oleh responsden.

\section{HASIL DAN PEMBAHASAN}

Kontruksi materi yang dibahas pada penelitian adalah materi yang disampaikan dapat meningkatkan keterampilan mahasiswa dalam memasak, kesesuaian dengan kebutuhan dan harapan mahasiswa, serta penggunaan teknologi sebagai media pembelajaran. Hasil penelitian tentang kontruksi materi dapat dilihat pada Tabel 2, 3, dan 4.

Tabel 2 Rekapitulasi Respons Materi yang Disampaikan Dapat Meningkatkan Keterampilan Memasak Mahasiswa

\begin{tabular}{ccc}
\hline No & Kriteria & Responsden \\
\hline 1 & Sangat rendah & 0 \\
2 & Rendah & 0 \\
3 & Cukup & 2 \\
4 & Tinggi & 15 \\
5 & Sangat tinggi & 13 \\
\hline & Total & $\mathbf{3 0}$ \\
\hline
\end{tabular}

Tabel 3 Rekapitulasi Respons Kesesuaian Materi dengan Kebutuhan dan Harapan Mahasiswa

\begin{tabular}{ccc}
\hline No & Kriteria & Responsden \\
\hline 1 & Sangat rendah & 0 \\
2 & Rendah & 0 \\
3 & Cukup & 1 \\
4 & Tinggi & 12 \\
5 & Sangat tinggi & 17 \\
\hline & Total & $\mathbf{3 0}$ \\
\hline
\end{tabular}


Tabel 4 Rekapitulasi Respons Penggunan Teknologi sebagai Media Pembelajaran

\begin{tabular}{ccc}
\hline No & Kriteria & Responsden \\
\hline 1 & Tidak pernah & 0 \\
2 & Jarang & 0 \\
3 & Kadang-kadang & 0 \\
4 & Sering & 10 \\
5 & Selalu & 20 \\
\hline & Total & $\mathbf{3 0}$
\end{tabular}

\section{Kompetensi Pedagogik}

Hasil analisis respons mahasiswa mengenai kesiapan dosen dalam memberi pelajaran pada mata kuliah teori maupun praktik, serta respons tentang keteraturan dan ketertiban penyelenggaraan perkuliahan. Secara rinci dapat dilihat pada Tabel 5 dan 6.

Tabel 5 Rekapitulasi Respons Kesiapan Dosen dalam Mata Kuliah Teori atau Praktik

\begin{tabular}{ccc}
\hline No & Kriteria & Responsden \\
\hline 1 & Tidak baik & 0 \\
2 & Kurang baik & 0 \\
3 & Cukup baik & 5 \\
4 & Baik & 13 \\
5 & Sangat baik & 12 \\
\hline & Total
\end{tabular}

Tabel 6 Rekapitulasi Respons Keteraturan dan Ketertiban Penyelenggaraan Perkuliahan

\begin{tabular}{ccc}
\hline No & Kriteria & Responsden \\
\hline 1 & Sangat rendah & 0 \\
2 & Rendah & 0 \\
3 & Cukup & 4 \\
4 & Tinggi & 16 \\
5 & Sangat tinggi & 10 \\
\hline & Total & $\mathbf{3 0}$ \\
\hline
\end{tabular}

Hasil analisis respons mahasiswa tentang kejelasan penyampaian materi, umpan balik, dan pelaksanaan evaluasi dapat dilihat pada Tabel 7, 8, dan 9 . 
Tabel 7 Rekapitulasi Respons tentang Penyampaian Materi

\begin{tabular}{ccc}
\hline No & Kriteria & Responsden \\
\hline 1 & Tidak baik & 0 \\
2 & Kurang baik & 0 \\
3 & Cukup baik & 5 \\
4 & Baik & 15 \\
5 & Sangat baik & 10 \\
\hline & Total & $\mathbf{3 0}$
\end{tabular}

Tabel 8 Rekapitulasi Respons tentang Penyampaian Umpan Balik

\begin{tabular}{ccc}
\hline No & Kriteria & Responsden \\
\hline 1 & Tidak baik & 0 \\
2 & Kurang baik & 1 \\
3 & Cukup baik & 4 \\
4 & Baik & 13 \\
5 & Sangat baik & 12 \\
\hline & Total & $\mathbf{3 0}$
\end{tabular}

Tabel 9 Rekapitulasi Respons tentang Pelaksanaan Evaluasi

\begin{tabular}{ccc}
\hline No & Kriteria & Responsden \\
\hline 1 & Tidak pernah & 0 \\
2 & Jarang & 3 \\
3 & Kadang-kadang & 6 \\
4 & Sering & 11 \\
5 & Selalu & 10 \\
\hline & Total & $\mathbf{3 0}$ \\
\hline
\end{tabular}

\section{Kompetensi Profesional}

Hasil analisis respons mahasiswa tentang kemampuan menjelaskan materi pokok secara tepat, kemampuan dosen memberi contoh-contoh yang relevan, dan waktu untuk membimbing di luar kelas yang terlihat pada Tabel 10, 11, dan 12.

Tabel 10 Rekapitulasi Respons tentang Materi Pokok secara Tepat

\begin{tabular}{ccc}
\hline No & Kriteria & Responsden \\
\hline 1 & Tidak baik & 0 \\
2 & Kurang baik & 0 \\
3 & Cukup baik & 3 \\
4 & Baik & 13 \\
5 & Sangat baik & 14 \\
\hline & Total & $\mathbf{3 0}$
\end{tabular}


Tabel 11 Rekapitulasi Respons tentang Kemampuan Memberi Contoh Relevan

\begin{tabular}{ccc}
\hline No & Kriteria & Responsden \\
\hline 1 & Tidak baik & 0 \\
2 & Kurang baik & 0 \\
3 & Cukup baik & 1 \\
4 & Baik & 9 \\
5 & Sangat baik & 20 \\
\hline & Total
\end{tabular}

Tabel 12 Rekapitulasi Respons tentang Waktu untuk Membimbing Belajar di Luar Kelas

\begin{tabular}{ccc}
\hline No & Kriteria & Responsden \\
\hline 1 & Tidak baik & 0 \\
2 & Kurang baik & 0 \\
3 & Cukup baik & 0 \\
4 & Baik & 13 \\
5 & Sangat baik & 17 \\
\hline & Total & $\mathbf{3 0}$ \\
\hline
\end{tabular}

\section{Kompetensi Kepribadian}

Hasil analisis respons mahasiswa terhadap kompetensi kepribadian dosen pengampu mata kuliah Operasional Tata Boga dilihat dari beberapa aspek, yaitu kewibawaan, kearifan dalam mengambil keputusan, sikap, dan perilaku sebagai pribadi dosen. Gambaran tentang persepsi mahasiswa terhadap beberapa aspek tersebut terlihat pada Tabel 13, 14, dan 15.

Tabel 13 Rekapitulasi Respons tentang Kewibawaan sebagai Pribadi Dosen

\begin{tabular}{ccc}
\hline No & Kriteria & Responsden \\
\hline 1 & Tidak baik & 0 \\
2 & Kurang baik & 0 \\
3 & Cukup baik & 3 \\
4 & Baik & 10 \\
5 & Sangat baik & 17 \\
\hline & Total & $\mathbf{3 0}$
\end{tabular}


Tabel 14 Rekapitulasi Respons tentang Kearifan dalam Mengambil Keputusan

\begin{tabular}{ccc}
\hline No & Kriteria & Responsden \\
\hline 1 & Tidak baik & 0 \\
2 & Kurang baik & 0 \\
3 & Cukup baik & 1 \\
4 & Baik & 15 \\
5 & Sangat baik & 14 \\
\hline & Total & $\mathbf{3 0}$ \\
\hline
\end{tabular}

Tabel 15 Rekapitulasi Respons tentang Sikap dan Perilaku

\begin{tabular}{ccc}
\hline No & Kriteria & Responsden \\
\hline 1 & Tidak baik & 0 \\
2 & Kurang baik & 0 \\
3 & Cukup baik & 4 \\
4 & Baik & 10 \\
5 & Sangat baik & 16 \\
\hline & Total & $\mathbf{3 0}$ \\
\hline
\end{tabular}

\section{Kompetensi Sosial}

Hasil analisis respons mahasiswa terhadap kompetensi sosial dosen pengampu mata kuliah Operasional Tata Boga dilihat dari beberapa aspek, seperti kemampuan dosen dalam menyampaikan pendapat, kemampuan menerima kritik, saran/pendapat orang lain, dan mudah bergaul. Analisis ketiga aspek tersebut dapat dilihat pada Tabel 16, 17, dan 18 .

Tabel 16 Rekapitulasi Respons tentang Menyampaikan Pendapat

\begin{tabular}{ccc}
\hline No & Kriteria & Responsden \\
\hline 1 & Tidak baik & 0 \\
2 & Kurang baik & 0 \\
3 & Cukup baik & 5 \\
4 & Baik & 14 \\
5 & Sangat baik & 11 \\
\hline & Total & $\mathbf{3 0}$ \\
\hline
\end{tabular}


Tabel 17 Rekapitulasi Respons Kemampuan Menerima Kritik, Saran, dan Pendapat Orang Lain

\begin{tabular}{ccc}
\hline No & Kriteria & Responsden \\
\hline 1 & Tidak baik & 0 \\
2 & Kurang baik & 0 \\
3 & Cukup baik & 3 \\
4 & Baik & 13 \\
5 & Sangat baik & 14 \\
\hline & Total & $\mathbf{3 0}$
\end{tabular}

Tabel 18 Rekapitulasi Respons tentang Sikap Mudah Bergaul

\begin{tabular}{ccc}
\hline No & Kriteria & Responsden \\
\hline 1 & Tidak baik & 0 \\
2 & Kurang baik & 0 \\
3 & Cukup baik & 0 \\
4 & Baik & 8 \\
5 & Sangat baik & 22 \\
\hline & Total
\end{tabular}

Kompetensi dosen, metode pengajaran, dan kualitas materi pembelajaran adalah faktor penting dalam prestasi akademik mahasiswa. Penguasaan materi oleh mahasiswa sangat diharapkan agar tujuan pembelajaran yang telah ditetapkan (Rohani, 2010). Acuan keberhasilan dosen dalam menyampaikan materi adalah seberapa dalamnya pemahaman mahasiswa terhadap materi tersebut (Mukhtar, 2017). Berdasarkan hasil penelitian pada mata kuliah Operasional Tata Boga, kompetensi dosen, metode pengajaran, dan kualitas materi pembelajaran yang disampaikan oleh dosen sangat berpengaruh terhadap peningkatan keterampilan mahasiswa dalam memasak. Hanya ada beberapa mahasiswa yang memberikan jawaban yang pada kategori cukup. Mahasiswa tersebut memiliki permasalahan pada materi yang luas bahasannya dan memilki waktu yang tidak sesuai.

Materi yang kurang dikuasi atau dianggap sulit dapat menghambat tercapainya tujuan pembelajaran dan tidak mendukung peningkatan keterampilan mahasiswa bisa menjadi kelemahan mata kuliah (Zukhaira dan Kuswardono, 2010). Jadi, sebaiknya dosen bisa membuat materi yang sesuai dengan kebutuhan, serta keterbatasan waktu yang dimiliki, agar tidak terjadi kesenjangan pemahaman 
antara mahasiswa. Selain materi pembelajaran, metode pembelajaran dan kompetensi dosen sangat mendukung prestasi akademik mahasiswa (Ganyaupfu, 2013).

Dosen dalam proses pembelajaran merupakan orang yang bertugas dalam penyampaian materi kepada mahasiswa, maka dosen harus mempunyai keterampilan mengajar yang baik agar atmosfir belajar lebih menarik. Jadi mahasiswa akan mempersepsikan dosen yang mengajar dengan positif. Kompetensi dosen berpengaruh terhadap pemahaman materi dan keberhasilan mahasiswa (Mulyadi dan Rozak, 2019; Sariani dan Nurhakim, 2018; Arpan dan Marpanaji, 2015; Suwarni, 2014; Bahri dan Lestari, 2014; Mediawati, 2010). Berdasarkan hasil penelitian yang dilakukan peneliti, persepsi mahasiswa untuk kompetensi dosen secara keseluruhan sangat baik, sehingga dapat diartikan bahwa dosen pengampu mata kuliah Operasional Tata Boga sudah dapat dikategorikan seorang yang profesional dibidangnya. Hanya ada beberapa mahasiswa yang memberikan jawaban yang pada kategori jarang dan kurang baik. Kedua kategori tersebut adalah umpan balik dan evaluasi.

Umpan balik merupakan suatu bagian penting dalam kegiatan belajarmengajar yang harus dilakukan oleh dosen. Umpan balik sangat memengaruhi motivasi dan minat belajar mahasiswa. Hal tersebut sesuai dengan hasil penelitian sebelumnya yang menyatakan bahwa umpan balik memberikan dampak terhadap minat dan hasil belajar (Nurbani, dkk., 2017; Anggela, 2015; Seruni dan Hikmah, 2014). Jadi, umpan balik yang dilakukan oleh dosen pada mata kuliah Operasional Tata Boga harus lebih sering dilakukan agar memberikan dampak yang positif pada minat dan motivasi belajar mahasiswa. Selain umpan balik, evaluasi juga menjadi poin penting yang harus dilakukan pembenahan oleh dosen. Evaluasi terdiri dari pengukuran dan penilaian yang berfungsi untuk pengambilan keputusan. Dosen mata kuliah Operasional Tata Boga harus lebih aktif dalam melaksanakan evaluasi, hal yang sering terlupakan adalah evaluasi pada saat mahasiswa melaksanakan persentasi di kelas.

Penggunaan media teknologi pada pembelajaran yang masih belum diterapkan pada mata kuliah Operasional Tata Boga. Kompetensi dosen yang baik 
harus juga didukung dengan teknologi agar mempermudah kerja dan memberikan keefektifan dalam mengajar. Teknologi mendorong perubahan dalam proses pembelajaran. Pembelajaran Operasional Tata Boga yang difasilitasi dengan teknologi akan sangat menarik bagi mahasisiwa serta akan berpengaruh pada peningkatan hasil belajar mahasiswa. Hasil penelitian terdahulu menyatakan bahwa penerapan media teknologi dapat meningkatkan minat peserta didik dan proses belajar yang berpusat pada peserta didik menjadi sesuatu yang menarik (Anih, 2018; Budiman, 2017; Rahmayanti, 2015; Budiana, dkk., 2015; Darmadi, 2015).

\section{SIMPULAN}

Berdasarkan hasil penelitian, disimpulkan bahwa: (1) Persepsi mahasiswa terhadap konstruksi materi telah sesuai dengan kebutuhan dan bermanfaat untuk meningkatkan keterampilan mahasiswa meskipun ada beberapa materi yang cukup sulit untuk dipahami; dan (2) Kompetensi dosen pengampu mata kuliah Operasional Tata Boga sangat baik dan dapat dikategorikan sebagai seorang dosen profesional. Namun tetap harus ada perbaikan atau peningkatan pada umpan balik, evaluasi, dan pemanfaatan media teknologi dalam proses pembelajaran.

\section{DAFTAR PUSTAKA}

Anggela, R. 2015. Hubungan antara Kompetensi Profesional Guru dan Motivasi Kerja Guru dengan Prestasi Belajar Geografi Siswa SMA di Kota Yogyakarta Tahun Ajaran 2012/2013. Edukasi: Jurnal Pendidikan, 13(1): 63-72.

Anih, E. 2018. Modernisasi Pembelajaran di Perguruan Tinggi Berbasis Teknologi Informasi dan Komunikasi. Jurnal Pendidikan Unsika, 4(2): 185196.

Arpan, M. \& Marpanaji, E. 2015. Faktor-Faktor Eksternal yang Memengaruhi Hasil Belajar Pemrograman Komputer Mahasiswa PTIK IKIP PGRI Pontianak. Jurnal Pendidikan Vokasi, 5(2): 195-208.

Bahri, S. \& Lestari, E. T. 2014. Tingkat Kompetensi Pedagogik Guru Sejarah SMA/MA dalam Memanfaatkan Pembelajaran Berbasis Komputer di Kota Pontianak. Edukasi: Jurnal Pendidikan, 12(2): 237-246.

Budiana, H. R., Sjafirah, N. A., \& Bakti, I. 2015. Pemanfaatan Teknologi Informasi dan Komunikasi dalam Pembelajaran bagi Para Guru SMPN 2 Kawali Desa Citeureup Kabupaten Ciamis. Jurnal Aplikasi Ipteks untuk Masyarakat, 4(1): 59-62. 
Budiman, H. 2017. Peran Teknologi Informasi dan Komunikasi dalam Pendidikan. Jurnal Pendidikan Islam, 8(1): 31-43.

Darmadi, H. 2015. Tugas, Peran, Kompetensi, dan Tanggung Jawab Menjadi Guru Profesional. Edukasi: Jurnal Pendidikan, 13(2): 161-174.

Ganyaupfu, E. M. 2013. Factors Influencing Academic Achievement in Quantitative Courses among Business Studends of Private Higher Education Institutions. Journal of Education and Practice, 4(15): 57-65.

Mediawati, E. 2010. Pengaruh Motivasi Belajar Mahasiswa dan Kompetensi Dosen terhadap Prestasi Belajar. Jurnal Pendidikan Ekonomi Dinamika Pendidikan, V(2): 134-146.

Mukhtar. 2017. Persepsi Mahasiswa terhadap Pelaksanaan Perkuliahan dan Hubungannya dengan Partisipasi Mahasiswa dalam Perkuliahan (Studi tentang Mahasiswa Semester Genap Jurusan Sosiologi Universitas Riau). Jom FISIP, 4(2): 1-15.

Mulyadi, A. \& Rozak, A. M. 2019. Pengaruh Kompetensi dan Profesionalisme Dosen Akuntansi terhadap Tingkat Pemahaman Mahasiswa Akuntansi. Journal Accounting Science, 3(1): 1-17.

Nurbani, Fatmawati, E., Lesmana, C., \& Koriaty, S. 2017. Persepsi Mahasiswa tentang Kompetensi Pedagogik dan Kompetensi Profesional Dosen terhadap Motivasi Belajar Mahasiswa pada IKIP PGRI Pontianak. Jurnal Pendidikan Informatika dan Sains, 6(2): 177-190.

Prasetijo, R. \& Ihalauw, J. 2005. Perilaku Konsumen. Yogyakarta: Andi Offset.

Rahmayanti. 2015. Penggunaan Media IT dalam Pembelajaran. Jurnal Ilmiah Circuit, 1(1): 85-97.

Rohani, A. 2010. Pengelolaan Pengajaran: Sebuah Pengantar Menuju Guru Profesional. Jakarta: Rineka Cipta.

Sariani, N. \& Nurhakim, I. 2018. Persepsi Mahasiswa terhadap Kompetensi Dosen Program Studi Pendidikan Geografi IKIP PGRI Pontianak. Sosial Horizon: Jurnal Pendidikan Sosial, 5(2): 228-243.

Sarwono, S. W. 2013. Pengantar Psikologi Umum. Jakarta: PT Raja Grafindo Persada.

Seruni \& Hikmah, N. 2014. Pemberian Umpan Balik dalam Peningkatan Hasil Balajar Mahasiswa. Jurnal Formatif, 4(3): 227-236.

Soraya, N. 2018. Analisis Persepsi Mahasiswa terhadap Kompetensi Dosen dalam Mengajar pada Program Studi PAI Fakultas Ilmu Tarbiyah dan Keguruan UIN Raden Fatah Palembang. Jurnal Tadrib, IV(1): 183-204.

Suwarni. 2014. Pembelajaran Sejarah di Sekolah Menengah Atas (Studi Kasus di SMA N 1 Prembun dan SMA N 1 Pejagoan Kabupaten Kebumen). Edukasi: Jurnal Pendidikan, 12(1): 124-137.

Undang-Undang Republik Indonesia Nomor 14 Tahun 2005 tentang Guru dan Dosen. http://luk.staff.ugm.ac.id/atur/UU14-2005GuruDosen.pdf. Diakses 20 Januari 2020.

Walgito, B. 2010. Pengantar Psikologi Umum. Yogyakarta: CV Andi.

Zukhaira \& Kuswardono, S. 2010. Persepsi dan Harapan Mahasiswa dan Dosen terhadap Pembelajaran Keterampilan Bahasa Arab. Jurnal Bahasa dan Sastra, 6(1): 1-7. 